\title{
Effects of Exogenous Glucose on Brain Ischemia in Ovine Fetuses
}

\author{
KATHERINE H. PETERSSON, HALIT PINAR, EDWARD G. STOPA, GRAZYNA B. SADOWSKA, \\ R. CHOUDARY HANUMARA, AND BARBARA S. STONESTREET
}

Department of Pediatrics [K.H.P., G.B.S., B.S.S.], Department of Pediatric Pathology [H.P.], Brown
University Medical School, Providence, Rhode Island 02905, Department of Pathology (Division of
Neuropathology) [E.G.S.], Women and Infants' Hospital of Rhode Island, Rhode Island Hospital,
Providence, Rhode Island 02905, and Department of Computer Science and Statistics [R.C.H.], The

Providence, Rhode Island 02905, and Department of Computer Science and Stats
University of Rhode Island, Kingston, Rhode Island 02881

\begin{abstract}
We examined the effects of prolonged moderate hyperglycemia with and without an additional rapid glucose injection on ischemic brain injury in the fetus. Twenty-five ewes (117-124 d of gestation) were assigned to one of four groups: 1) glucoseinfused fetuses exposed to $30 \mathrm{~min}$ of carotid artery occlusion followed by $48 \mathrm{~h}$ of reperfusion (I/R-Glu, $n=8$ ); 2) glucoseinfused plus rapid glucose injection given $100 \mathrm{~min}$ before $30 \mathrm{~min}$ of occlusion followed by $48 \mathrm{~h}$ of reperfusion (I/R-GluR, $n=4$ ); 3) placebo-infused exposed to $30 \mathrm{~min}$ of occlusion and $48 \mathrm{~h}$ of reperfusion (I/R-PL, $n=8)$; and 4) glucose-infused sham occlusion and $48 \mathrm{~h}$ of sham reperfusion (control, $n=5$ ). After baseline measurements, fetuses were infused with glucose $(9-16 \mathrm{mg} / \mathrm{kg} /$ $\min$ ) for $48 \mathrm{~h}$ before and after carotid occlusion or sham treatment. The I/R-PL group received $0.9 \% \mathrm{NaCl}$. Brain pathologic outcome was determined. Serial sections stained with Luxol fast blue-hematoxylin and eosin were scored for white matter, cerebral cortical, and hippocampal lesions. These areas received graded pathologic scores of 0 to 5 , reflecting the amount of injury, where $0=0 \%, 1=1-25 \%, 2=26-50 \%, 3=51-75 \%$, $4=76-95 \%$, and $5=96-100 \%$ of the area damaged. Compar-
\end{abstract}

\section{ABSTRACT}

isons of the pathologic scores for cerebral cortex (CC), white matter (WM), and hippocampus $(\mathrm{H})$ demonstrated that the I/RGluR (CC: $4.56 \pm 0.11, \mathrm{WM}: 4.50 \pm 0.11, \mathrm{H}: 3.44 \pm 0.48$, mean \pm SEM) had more $(p<0.05)$ damage than the I/R-Glu (CC: 2.46 $\pm 0.47, \mathrm{WM}: 1.97 \pm 0.37, \mathrm{H}: 1.81 \pm 0.36)$ and control $(\mathrm{CC}$ : $1.12 \pm 0.13, \mathrm{WM}: 0.82 \pm 0.34, \mathrm{H}: 0.80 \pm 0.34)$ groups. The pathologic scores in the I/R-Glu were $(p<0.05)$ greater than the control, but not the I/R-PL (CC: $2.12 \pm 0.35$, WM: $2.20 \pm 0.44$, $\mathrm{H}: 1.59 \pm 0.41)$ group. We conclude that exposure to prolonged moderate hyperglycemia before ischemia and during reperfusion does not affect the extent of brain injury, but exposure to an additional acute increase in plasma glucose concentration before ischemia is extremely detrimental to the fetal brain. (Pediatr Res 56: 621-629, 2004)
EcoG, electrocorticogram
Glu, glucose
$\mathbf{I} / \mathbf{R}$, ischemia and $48 \mathrm{~h}$ of reperfusion
PL, placebo

Hypoxic/ischemic brain injury is the single most important neurologic problem occurring during the perinatal period $(1,2)$. Perinatal CNS lesions are particularly common in pregnancies complicated by poorly controlled diabetes mellitus, intrauterine growth retardation, and premature delivery. Infants born to women with these pregnancy complications are also at high risk for perturbations in systemic glucose homeostasis (3-6). Exposure to hyperglycemia before or during a hypoxic/ ischemic episode could predispose infants to the development

Received February 11, 2004; accepted May 24, 2004.

Correspondence: Barbara S. Stonestreet, M.D., Brown University Medical School, Department of Pediatrics, Women and Infants' Hospital of Rhode Island, 101 Dudley Street, Providence, RI 02905-240; e-mail: bstonest@wihri.org

Supported by Diabetes Center Grant P50 HD11343 and R01-HD34618.

DOI: 10.1203/01.PDR.0000139415.96985.BF of cerebral palsy, intellectual deficit, and mental retardation $(7,8)$.

Fetuses of women with poorly controlled diabetes mellitus can be exposed to acute and/or prolonged hyperglycemia $(4,9)$. The offspring exhibit increased incidences of macrosomia, respiratory distress syndrome, cardiovascular abnormalities, perinatal asphyxia, hypoxemia, mortality, and sudden fetal demise $(4-6,9)$. In the human fetus, hyperglycemia has been implicated as a major factor in the pathogenesis of many of these morbidities $(5,6)$. Abnormalities in systemic glucose homeostasis also are common in infants with congenital diabetes, infants with sepsis, premature infants, and premature infants exposed to corticosteroids $(4,5)$. Prolonged and/or acute hyperglycemia can complicate these conditions. Critically ill premature infants may develop hypoxia, hypotension, pneumothoraces, and hemodynamic compromise under a variety of 
circumstances, and these conditions can be associated with the development of brain damage $(10,11)$. Therefore, both human fetuses and premature infants potentially can be exposed to circumstances in which they are vulnerable to developing acute and/or prolonged hyperglycemia and brain injury.

In the adult, hyperglycemia is thought to exacerbate hypoxic/ischemic brain injury (12-16). The mechanism(s) by which the hyperglycemia intensifies brain damage is the subject of much controversy (15-20). The role of hyperglycemia in perinatal hypoxic-ischemic CNS insults has not been completely elucidated. Whether or not increases in glucose concentrations before and during perinatal hypoxic-ischemic episodes are detrimental or beneficial to the immature CNS remains uncertain. Increases in glucose have been reported to promote survival $(21)$, not to affect $(22,23)$ and to exacerbate CNS damage $(24,25)$.

Glucose-pretreated or glucose-fed juvenile monkeys exposed to cardiovascular arrest develop brain edema, widespread cerebral injury, and impaired blood-brain barrier function, whereas food-deprived monkeys recover (26). Several studies have demonstrated that hyperglycemia in conjunction with hypoxic/ischemic episodes in piglets accentuates the decreases in brain $\mathrm{pH}$, increases in the production of lactate and lipid peroxidation products, and increases pathologic damage (27-29). In exteriorized asphyxiated fetal sheep, hyperglycemia was associated with reduced cerebral oxygen consumption and deterioration of the somatosensory evoked potentials (24) and in the newborn dog, hyperglycemia accentuated brain damage in select brain regions (30).

In contrast to the studies outlined above, the outcome was improved in hypoxic-hyperglycemic compared with hypoxicnormoglycemic piglets (31). Immature anoxic mice pretreated with glucose survived longer than anoxic control mice (21), elevated blood glucose concentrations preserved energy reserves in immature rats (32) and electroencephalographic activity in fetal sheep (33) and glucose concentration did not affect the rate of lactate accumulation in young rabbits or neonatal dogs subjected to cerebral ischemia (22).

The studies summarized above used divergent methods to achieve the hyperglycemia, with large ranges in infusion times and varying concentrations of glucose. Pathologic findings of these studies focused predominantly on the cerebral cortex, disregarding potential injury to white matter.

Similar to the human, the sheep has a relatively long gestation and a mature brain at birth (34). The sheep fetus has been used extensively for physiologic and pathophysiological studies of the brain (35-40). Studies have not examined the pathologic consequences of an acute and/or prolonged exposure to hyperglycemia on brain ischemia in a fetal subject. As outlined above, fetuses of poorly controlled diabetic women and premature infants can be exposed to acute and prolonged increases in systemic glucose concentrations and conditions that potentially result in brain damage.

In this study, we examined the effects of prolonged moderate hyperglycemia with and without an additional rapid injection of glucose on ischemic brain injury in the ovine fetus. We used the methods of Williams et al. (41) to induce ischemia by bilateral occlusion of the carotid arteries after ligation of the vertebral-occipital anastomoses. We have previously examined the severity of the damage in white matter, cerebral cortex, and hippocampus with a modification of the scoring system established by Williams et al. (41) on whole brain sections stained with Luxol fast blue-hematoxylin and eosin (40).

\section{MATERIALS AND METHODS}

This study was conducted after approval by the Institutional Animal Care and Use Committees of Brown University and Women and Infants' Hospital of Rhode Island and according to the National Institutes of Health Guidelines for the use of experimental animals.

Animal preparation. Surgery was performed on 25 mixed breed ewes from 117 to $124 \mathrm{~d}$ of gestation. Anesthesia was induced in the ewes by an intramuscular injection of ketamine and maintained with $1-2 \%$ halothane and oxygen after endotracheal intubation. The uterus was exposed by a midline abdominal incision, and the fetus operated on through a hysterotomy with minimal loss of amniotic fluid $(42,43)$. Polyvinyl catheters were placed into a brachial artery and advanced to the thoracic aorta for blood sample withdrawal, into a femoral artery and advanced into the thoracic aorta for heart rate and blood pressure monitoring, and into a brachial vein for drug or glucose administration. An amniotic fluid catheter was placed as a referent for fetal arterial blood pressure.

The fetal carotid arteries were exposed caudal to the angle of the mandible (41). Two inflatable 4-mm vascular occluders (In Vivo Metric, Healdsburg, CA) were placed around each carotid artery at the level of the $3^{\text {rd }}$ to $5^{\text {th }}$ vertebrae; a total of four occluders were placed in each fetus $(41,44)$. This was done so that, if one occluder did not function properly, the second occluder could be relied upon for the occlusion (41). The vertebral-occipital anastomoses proximal to occluder were ligated to restrict blood flow from the vertebral circulation $(41,44)$. The lingual arteries were ligated to restrict noncerebral blood flow. For EcoG measurement, two pairs of stainless steel screws (size 0-80, Small Parts, Inc., Miami Lakes, FL) were implanted via burr holes into the fetal skull and onto the dura. They were placed overlying the parietal cortex $3 \mathrm{~mm}$ posterior to the bregma and $3 \mathrm{~mm}$ anterior to the intersection of the sagittal and occipital sutures with each $15 \mathrm{~mm}$ lateral to the sagittal suture as previously described (41). A reference electrode also was sewn to the scalp. The stainless steel screws were connected to the recorder by shielded polyvinyl chlorideinsulated wires $0.25 \mathrm{~mm}$ in diameter (Alpha Wire Co., Elizabeth, NJ). The EcoG was performed in the fetal sheep to determine that it became isoelectric during the cerebral ischemia (41).

The ewes were permitted a recovery of $4-7 \mathrm{~d}$ after surgery. The vascular catheters were flushed every other day with heparinized saline $(10 \mathrm{U} / \mathrm{mL})$ to maintain patency. Antibiotics (1 $\mathrm{g}$ ampicillin and $10 \mathrm{mg}$ amikacin) were administered to the ewe intramuscularly daily for $3 \mathrm{~d}$ after surgery. In addition, the fetus was given ampicillin $(100 \mathrm{mg} / \mathrm{kg})$ and amikacin $(5 \mathrm{mg} /$ $\mathrm{kg}$ ) on each day the catheters were flushed. Studies were performed on the fetus if the fetal arterial blood gases were within the normal range $\left(\mathrm{pH}>7.30, \mathrm{PaO}_{2}>18\right.$, and $\mathrm{PaCO}_{2}<$ 
$60 \mathrm{~mm} \mathrm{Hg}$ at $39.5^{\circ} \mathrm{C}$ ). None of the ewes exhibited signs of infection between the initial instrumentation and the experimental studies. The temperatures of ewes with the shamoperated fetuses were the same as those of the experimental groups $\left(38.4-38.7^{\circ} \mathrm{C}\right)$.

Experimental protocol and methodology. Four to seven days after surgery, animals were assigned to one of four groups: 1) glucose-infused fetuses exposed to $30 \mathrm{~min}$ of bilateral carotid artery occlusion followed by $48 \mathrm{~h}$ of reperfusion (I/R-Glu, $n=8) ; 2$ ) glucose-infused fetuses plus rapid glucose injection ( $1 \mathrm{~g} / \mathrm{kg}$ i.v. glucose; peak concentration: $7.22 \mathrm{mM})$ given $100 \mathrm{~min}$ before $30 \mathrm{~min}$ of carotid occlusion and followed by $48 \mathrm{~h}$ of reperfusion (I/R-GluR, $n=4) ; 3$ ) placebo-infused fetuses, $30 \mathrm{~min}$ of carotid occlusion and $48 \mathrm{~h}$ of reperfusion (I/R-PL, $n=8$ ); and 4) glucose-infused, sham-treated fetuses without occlusion and $48 \mathrm{~h}$ of sham reperfusion (control, $n=$ 5 ). The fetuses were assigned to the above groups, before the onset of the experiments, generally such that at any one time we studied two animals simultaneously: an I/R-Glu and control fetus, or I/R-Glu and I/R-GluR. The I/R-PL group has been reported previously, but studied over the same time interval (40). It was included here for comparison with the I/R-Glu group, to limit unnecessary animal usage and was justified, because the studies were performed using the same study design (40).

Fetal sheep were infused with glucose $(9-16 \mathrm{mg} / \mathrm{kg} / \mathrm{min}$, plasma concentration: $2.4-3.7 \mathrm{mM}$ ) continuously for $48 \mathrm{~h}$ before, during, and $48 \mathrm{~h}$ after the $30 \mathrm{~min}$ of carotid occlusion or sham treatment (no occlusion) for a total of $96 \mathrm{~h}$. The objective of the continuous glucose infusion was to maintain 2to 3 -fold increases in fetal plasma glucose concentrations over baseline values (baseline range, $0.9-1.5 \mathrm{mM}$ ) for the $96-\mathrm{h}$ study. The plasma glucose concentrations of the fetuses were measured twice daily to adjust the infusion rates to achieve the targeted range of plasma glucose concentrations. For the purpose of this study, exposure to the 2- to 3 -fold increases in plasma glucose concentrations for $96 \mathrm{~h}$, i.e. $48 \mathrm{~h}$ before, during, and after carotid occlusion or sham treatment was considered prolonged moderate hyperglycemia. The placebo treated group (I/R-PL) received a continuous infusion of $0.9 \%$ $\mathrm{NaCl}$.

In the I/R-GluR group, the fetal sheep received the same prolonged glucose infusion rate as outlined above. In addition, an injection of i.v. glucose ( $1 \mathrm{~g} / \mathrm{kg}$ of estimated fetal weight) was given rapidly $100 \mathrm{~min}$ before the onset of carotid occlusion. We added this group to our study, because, during preliminary studies, we had inadvertently found that a rapid infusion of glucose in addition to the continuous infusion resulted in severe brain damage in the fetus. We also included this group, because premature infants who develop hyperglycemia, during parenteral alimentation, corticosteroid treatment, etc. can experience severe acute episodes of hyperglycemia superimposed upon moderate elevations in plasma glucose.

Cerebral ischemia was induced by inflating the carotid artery occluders with $0.9 \% \mathrm{NaCl}$ for $30 \mathrm{~min}$. In the control sham group, the occluders were not inflated. An isoelectric EcoG was used to ensure the reproducibility of cerebral ischemia (41).
Arterial $\mathrm{pH}$, blood gases, heart rate, mean arterial blood and amniotic fluid pressures, and plasma glucose and lactate concentrations were measured on the fetus at baseline $(-48 \mathrm{~h})$, $-24 \mathrm{~h},-1.5 \mathrm{~h}, 15 \mathrm{~min}, 1,2,24$, and $48 \mathrm{~h}$ after cerebral ischemia or control sham treatment. Heart rate and mean arterial blood and amniotic fluid pressures in fetal sheep were measured with pressure transducers (Model 1280 C, HewlettPackard, Lexington, MA) and recorded on a polygraph (Model 17758 B Series, Hewlett Packard). For fetal EcoG measurements, the parietal EcoG was amplified, filtered, and recorded by a Grass Instruments recording system $(30-\mathrm{Hz}$ low-pass filter, 7 PI preamplifier, DC driver, model 70, Grass Instruments Co., Quincy, MA). The EcoG was monitored and intermittently recorded.

Blood gases and $\mathrm{pH}$ were measured on a Corning blood gas analyzer (Model 238, Corning Scientific, Medford, MA) corrected to $39.5^{\circ} \mathrm{C}$ for the fetus and $38.5^{\circ} \mathrm{C}$ for the ewe. Plasma glucose and lactate concentrations were determined in duplicate using a glucose/lactate analyzer (YSI 2300 STAT, YSI Inc., Yellow Springs, OH).

Brain removal and pathologic methods. At the end of the reperfusion period, the ewe was given i.v. pentobarbital (15-20 $\mathrm{mg} / \mathrm{kg}$ ) to achieve a surgical plane of anesthesia. A hysterotomy was performed and the fetus was withdrawn from the uterus with the umbilical circulation intact. The brain was rapidly removed and immersion fixed in $10 \%$ formalin. Then the ewe was killed with pentobarbital $(100-200 \mathrm{mg} / \mathrm{kg})$.

Formalin-fixed whole brains were coronally cut at $1-\mathrm{cm}$ intervals into six serial brain slices and paraffin embedded. The brain regions located within each slice are as follows: slice 1 (S1) was prefrontal cortex, slice 2 (S2) was frontal cortex, slice 3 (S3) was posterior medial eminence, slice 4 (S4) was parietal-occipital junction, slice 5 (S5) was occipital pole, and slice 6 (S6) was cerebellum and brainstem. Eight-micrometer-thick histologic sections from each paraffin-embedded block were routinely deparaffinized, rehydrated, and stained with Luxol fast blue in combination with hematoxylin and eosin to delineate clearly the white matter lesions.

The well-established scoring system of Williams et al. (41) was modified to include both white matter and neuronal scores (40). The whole mount coronal sections were scored by two pathologists for white matter, cerebral cortical, and hippocampal lesions. The pathologists scored the brain sections without knowledge of the treatment groups. Myelin degradation and reactive gliosis were indicative of white matter damage $(41,45)$. Nuclear pyknosis, cytoplasmic reddening and condensation, and hyperchromatism were indicative of neuronal injury. The pathologists scored the most severely injured area of each section using the following pathologic scoring system $(0-5)$, where $0=0 \%, 1=1-25 \%, 2=26-50 \%, 3=51-75 \%$, $4=76-95 \%$, and $5=96-100 \%$ of the area damaged.

Statistical analysis. All results were expressed as mean \pm SEM. Serial measurements of physiologic variables were compared by two-factor ANOVA for repeated measures with group and time as the factors (46). If a significant difference was found by ANOVA, the variables were further compared by a two-group $t$ test corrected for multiple comparisons by the Bonferroni method to detect specific differences between 
groups. To further describe and enhance the statistically significant effects of treatment over time, separate ANOVA for repeated measures were performed within each group. If a significant difference was found by ANOVA, the NewmanKeuls posthoc test was used to identify specific differences within the groups.

The brain scores were analyzed by ANOVA for repeated measures for three factors with slice, region, and group as the factors. A repeated-measures ANOVA was applied to the brain slices, because multiple slices were examined within the same brain. Initially, the pathologists were analyzed as an additional factor in the model. This analysis demonstrated that there were no statistically significant differences between the two pathologists. Therefore, the scores by both pathologists were averaged to obtain the final scores for each brain section. Although the scores represent ordinal rather than continuous data, we used parametric ANOVA procedures to analyze the scores rather than nonparametric statistical analysis, because the averages of the pathologists' scores tended to be continuous and examination of residuals indicated that the normality assumption was tenable. The calculations were done using the Statistical Analysis Program (SAS Institute, Cary, NC) (47). The results were considered statistically significant whenever the $p$ value was $<0.05$.

\section{RESULTS}

Physiologic variables. Arterial $\mathrm{pH}$, carbon dioxide tension, and base excess were within normal physiologic ranges for our laboratory (42) and did not change during the study periods within or between groups, except for the increases in the carbon dioxide tension after brain ischemia in the I/R-Glu compared with the I/R-PL group (Table 1). The higher carbon dioxide tension in the I/R-Glu group was most likely a result of accelerated fetal metabolism because of the glucose infusions (48). Small variations in arterial $\mathrm{Pao}_{2}$, heart rate, and mean arterial blood pressure among the study periods and groups were within normal physiologic range, and probably not of major physiologic consequences.

Plasma glucose concentrations increased significantly from baseline values during the continuous glucose infusions in the control, I/R-Glu, and I/R-GluR groups (ANOVA: within groups, all times differ from baseline i.e., $-48 \mathrm{~h}, p<0.05$ ), but did not differ significantly among the groups (Fig. 1). In the placebo infused I/R-PL group, there was a small increase in plasma glucose concentration after ischemia. After the onset of the glucose infusions, plasma glucose concentrations were higher in the I/R-Glu than in the I/R-PL group. Plasma lactate concentrations also increased significantly over time from baseline in the control group (ANOVA: within group all times differ from baseline, i.e. $-48 \mathrm{~h}, p<0.05)$ and, in the placebo-infused I/R-PL group, after brain ischemia. Although the lactate values appeared to increase during the studies in the I/R-Glu and I/R-GluR groups, the changes were not statistically significant most likely because of the large standard errors of the mean in the fetuses exposed to cerebral ischemia and exogenous glucose infusions (Fig. 1). All of the fetuses in the I/R-Glu, I/R-PL, and I/R-GluR groups, but not in the control group, exhibited isoelectric EcoG tracings during the $30 \mathrm{~min}$ of bilateral carotid artery occlusion.

Table 1. Physiological variables for study groups by study period

\begin{tabular}{|c|c|c|c|c|c|c|c|c|}
\hline & \multirow[b]{2}{*}{ Group } & \multirow[b]{2}{*}{ Baseline -48} & \multicolumn{6}{|c|}{ Time relative to ischemia/sham-ischemia (h) } \\
\hline & & & -24 & 0.25 & 1 & 2 & 24 & 48 \\
\hline \multirow[t]{4}{*}{$\mathrm{pH}$} & Control & $7.35 \pm 0.01$ & $7.28 \pm 0.06$ & $7.32 \pm 0.02$ & $7.32 \pm 0.02$ & $7.32 \pm 0.02$ & $7.33 \pm 0.01$ & $7.33 \pm 0.01$ \\
\hline & I/R-Glu & $7.33 \pm 0.01$ & $7.29 \pm 0.02$ & $7.31 \pm 0.02$ & $7.29 \pm 0.03$ & $7.30 \pm 0.02$ & $7.32 \pm 0.01$ & $7.31 \pm 0.01$ \\
\hline & I/R-PL & $7.34 \pm 0.01$ & $7.33 \pm 0.01$ & $7.32 \pm 0.02$ & $7.32 \pm 0.01$ & $7.33 \pm 0.01$ & $7.34 \pm 0.01$ & $7.33 \pm 0.01$ \\
\hline & I/R-GluR & $7.34 \pm 0.02$ & $7.34 \pm 0.02$ & $7.31 \pm 0.03$ & $7.32 \pm 0.03$ & $7.33 \pm 0.01$ & $7.35 \pm 0.02$ & $7.33 \pm 0.02$ \\
\hline \multirow{4}{*}{$\mathrm{PaO}_{2}(\mathrm{~mm} \mathrm{Hg})$} & Control & $24 \pm 2 *$ & $24 \pm 2 *$ & $24 \pm 1^{*}$ & $24 \pm 1 *$ & $23 \pm 1 *$ & $23 \pm 1 *$ & $20 \pm 1$ \\
\hline & I/R-Glu & $25 \pm 1 \dagger$ & $24 \pm 1$ & $24 \pm 1 \dagger$ & $22 \pm 1$ & $23 \pm 1$ & $22 \pm 1$ & $22 \pm 1$ \\
\hline & I/R-PL & $24 \pm 1$ & $23 \pm 1$ & $26 \pm 1$ & $24 \pm 1$ & $24 \pm 1$ & $25 \pm 1$ & $24 \pm 1$ \\
\hline & I/R-GluR & $23 \pm 1$ & $21 \pm 1$ & $23 \pm 2$ & $22 \pm 1$ & $22 \pm 1$ & $21 \pm 2$ & $22 \pm 2$ \\
\hline \multirow{4}{*}{$\mathrm{PaCO}_{2}(\mathrm{~mm} \mathrm{Hg})$} & Control & $51 \pm 3$ & $51 \pm 2$ & $52 \pm 1$ & $51 \pm 2$ & $51 \pm 1$ & $53 \pm 2$ & $53 \pm 2$ \\
\hline & I/R-Glu & $53 \pm 1$ & $55 \pm 1$ & $53 \pm 1$ & $56 \pm 1$ & $56 \pm 1$ & $56 \pm 1$ & $56 \pm 1$ \\
\hline & I/R-PL & $53 \pm 1$ & $53 \pm 1$ & $50 \pm 2$ & $51 \pm 1 \S$ & $49 \pm 1 \S$ & $50 \pm 1 \S$ & $51 \pm 1 \S$ \\
\hline & I/R-GluR & $51 \pm 2$ & $54 \pm 3$ & $52 \pm 1$ & $53 \pm 1$ & $51 \pm 2$ & $51 \pm 1$ & $53 \pm 2$ \\
\hline \multirow[t]{4}{*}{ Base excess $(\mathrm{mEq} / \mathrm{L})$} & Control & $1.8 \pm 1$ & $-2.2 \pm 3$ & $0.5 \pm 1$ & $0.5 \pm 1$ & $0.0 \pm 1$ & $1.8 \pm 1$ & $1.9 \pm 1$ \\
\hline & I/R-Glu & $1.6 \pm 1$ & $0.0 \pm 2$ & $0.1 \pm 1$ & $-0.5 \pm 2$ & $0.2 \pm 1$ & $1.7 \pm 1$ & $1.5 \pm 1$ \\
\hline & I/R-PL & $2.3 \pm 1 \ddagger$ & $1.8 \pm 1 \ddagger$ & $-0.7 \pm 1$ & $0.4 \pm 1$ & $0.5 \pm 1$ & $1.0 \pm 1$ & $1.0 \pm 1$ \\
\hline & I/R-GluR & $1.5 \pm 2$ & $3.0 \pm 1$ & $-0.1 \pm 3$ & $1.0 \pm 2$ & $0.7 \pm 1$ & $2.6 \pm 1$ & $1.8 \pm 2$ \\
\hline \multirow[t]{4}{*}{ Heart rate (beats/min) } & Control & $178 \pm 8$ & $195 \pm 15$ & $197 \pm 7$ & $189 \pm 5$ & $185 \pm 4$ & $203 \pm 16$ & $172 \pm 10$ \\
\hline & I/R-Glu & $168 \pm 6 \ddagger$ & $176 \pm 6+$ & $207 \pm 10$ & $186 \pm 12$ & $179 \pm 5$ & $191 \pm 12$ & $165 \pm 10$ \\
\hline & I/R-PL & $179 \pm 7$ & $187 \pm 12$ & $205 \pm 13$ & $175 \pm 9$ & $169 \pm 9$ & $180 \pm 10$ & $177 \pm 8$ \\
\hline & I/R-GluR & $171 \pm 9$ & $192 \pm 17$ & $201 \pm 5$ & $175 \pm 5$ & $180 \pm 8$ & $191 \pm 6$ & $184 \pm 8$ \\
\hline \multirow[t]{4}{*}{ MAP (mm Hg) } & Control & $48 \pm 3$ & $55 \pm 4$ & $47 \pm 1$ & $49 \pm 2$ & $47 \pm 3$ & $45 \pm 4$ & $48 \pm 4$ \\
\hline & I/R-Glu & $56 \pm 2$ & $48 \pm 3$ & $53 \pm 3$ & $49 \pm 3$ & $50 \pm 3$ & $54 \pm 4$ & $55 \pm 4$ \\
\hline & I/R-PL & $51 \pm 2$ & $46 \pm 3$ & $49 \pm 3$ & $49 \pm 2$ & $45 \pm 3$ & $50 \pm 3$ & $54 \pm 4$ \\
\hline & I/R-GluR & $42 \pm 5 \S$ & $53 \pm 3$ & $44 \pm 3$ & $46 \pm 3$ & $42 \pm 4$ & $55 \pm 5$ & $48 \pm 5$ \\
\hline
\end{tabular}

Values are means $\pm \mathrm{SEM} . \mathrm{PaO}_{2}$ and $\mathrm{PaCO}_{2}$, arterial oxygen and carbon dioxide tension, respectively; MAP, mean arterial blood pressure.

$* p<0.05$ vs $48 \mathrm{~h}$ within group; $\dagger p<0.05$ vs $1 \mathrm{~h}$ within group; $\$ p<0.05$ vs $0.25 \mathrm{~h}$ within group; $\S p<0.05$ vs $\mathrm{I} / \mathrm{R}$-Glu group at the same time period. 


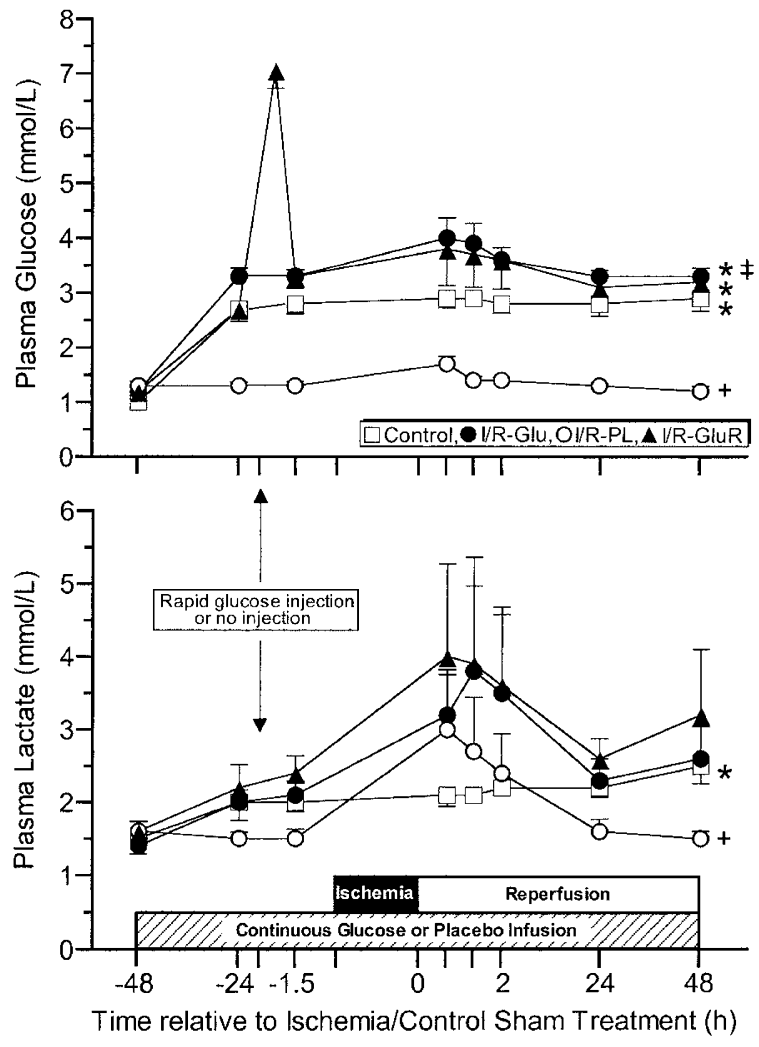

Figure 1. Plasma glucose and lactate concentrations during the study periods in the continuously glucose-infused ovine fetuses $(9-16 \mathrm{mg} / \mathrm{kg} / \mathrm{min})$ exposed to either control sham treatment (Control, $n=5$ ), $30 \mathrm{~min}$ of bilateral carotid artery occlusion followed by $48 \mathrm{~h}$ reperfusion (I/R-Glu, $n=8$ ) or $30 \mathrm{~min}$ of bilateral carotid artery occlusion followed by $48 \mathrm{~h}$ reperfusion and an additional rapid injection of glucose $(1 \mathrm{~g} / \mathrm{kg}$ IV glucose) given $100 \mathrm{~min}$ before carotid occlusion (I/R-GluR, $n=4$ ), and in the continuously placebo-infused ovine fetuses exposed to $30 \mathrm{~min}$ of bilateral carotid artery occlusion followed by $48 \mathrm{~h}$ reperfusion (I/R-PL, $n=8)$. Values are mean \pm SEM. When SE bars are not shown, the values for the SE are contained within the size of the symbols. "ANOVA: Within groups, all times differ from baseline, i.e., $-48 \mathrm{~h}$, $p<0.05 ;{ }^{+}$ANOVA: Within I/R-PL group, all times differ from $0.25 \mathrm{~h}$; $\$$ ANOVA: Differs from I/R-Glu after the onset of the glucose infusions.

Pathology. Representative whole mount (Fig. 2A), white matter (Fig. 2B) and cerebral cortex (Fig. 2C) coronal brain sections stained with Luxol fast blue-hematoxylin and eosin from the glucose-infused fetuses exposed to control treatment (Control), glucose-infused fetuses exposed to bilateral carotid artery occlusion followed by $48 \mathrm{~h}$ of reperfusion (I/R-Glu), placebo-infused fetuses exposed to carotid occlusion and $48 \mathrm{~h}$ of reperfusion (I/R-PL), and glucose-infused fetuses plus rapid glucose injection given before carotid occlusion followed by $48 \mathrm{~h}$ of reperfusion (I/R-GluR) are illustrated in Figure 2. The coronal sections from the control fetus exhibited healthyappearing cerebral cortex and intragyral white matter with homogenously blue-stained myelin. In contrast, the sections from the fetuses exposed to glucose infusion before and during ischemia/reperfusion (I/R-Glu) exhibited damage to the cerebral cortex and white matter. These areas showed pallor on Luxol fast blue staining and thinning of the cerebral cortex indicating white matter and neuronal loss, respectively. The sections from the placebo-infused fetuses exposed to ischemia/ reperfusion (I/R-PL) exhibited a comparable amount of dam- age to the cerebral cortex and white matter. The sections from the I/R-GluR group that had received the additional rapid injection of glucose before ischemia exhibited severe neuronal loss in the cerebral cortex and extensive intragyral white matter loss, manifested by marked pallor on Luxol fast blue staining and microscopic foci of cystic degeneration in both the cortex and white matter.

The pathologic scores of the coronally sliced whole brain sections demonstrated that the I/R-Glu group exhibited greater damage across the six brain slices when compared with the slices of the control group. Each individual brain slice from the I/R-Glu group was significantly more damaged than the corresponding slice from the control group (Fig. 3). The I/R-PL group has been previously reported (40), but was included here for comparison with the I/R-Glu group. The pathologic scores of the whole brain sections of the I/R-PL and I/R-Glu groups did not differ significantly. The pathologic scores of the whole brain sections of the I/R-GluR group exhibited more severe damage across the six brain slices when compared with the slices of the control and the I/R-Glu group. Each individual brain slice from the I/R-GluR group was significantly more damaged than the respective slices from both the I/R-Glu and control groups (Fig. 3).

The six slices were averaged to obtain the pathologic scores for the cerebral cortex, white matter, and hippocampus (Fig. 4). Results from the averaged scores indicated the I/R-GluR scores were significantly greater in the three regions when compared with the control and I/R-Glu groups. Although the injury in the cerebral cortex, white matter, and hippocampus appeared greater in the I/R-Glu group when compared with the control sham group, statistical significance was not observed, possibly reflecting our small sample size and the variability of the individual responses to ischemia. We cannot rule out the possibility that an increase in the number of animals examined might have clarified whether changes could be detected in the I/R-Glu group. There were no significant differences in the quantity of brain injury between the glucose and placebo infused groups exposed to ischemia/reperfusion.

\section{DISCUSSION}

We examined the effects of moderate prolonged hyperglycemia with (I/R-GluR) and without (I/R-Glu) an additional rapid injection of glucose on ischemic brain injury in ovine fetuses at $80 \%$ of gestation. Cerebral ischemia was induced by ligation of the vertebral-occipital anastomoses and bilateral occlusion of the carotid arteries according to established procedures $(40,41)$. The scoring system of Williams et al. (41) was modified to include both white matter and neuronal scores (40). The pathologic scores of the coronally sliced whole brain sections stained with Luxol fast blue-hematoxylin and eosin of fetuses exposed to prolonged moderate hyperglycemia and ischemia exhibited greater damage than the glucose-infused nonischemic control animals and a similar quantity of damage to our previously reported fetal sheep exposed to normoglycemic ischemia (40). When an additional rapid glucose injection was given before the induction of ischemia, the fetuses developed extremely severe brain damage. 

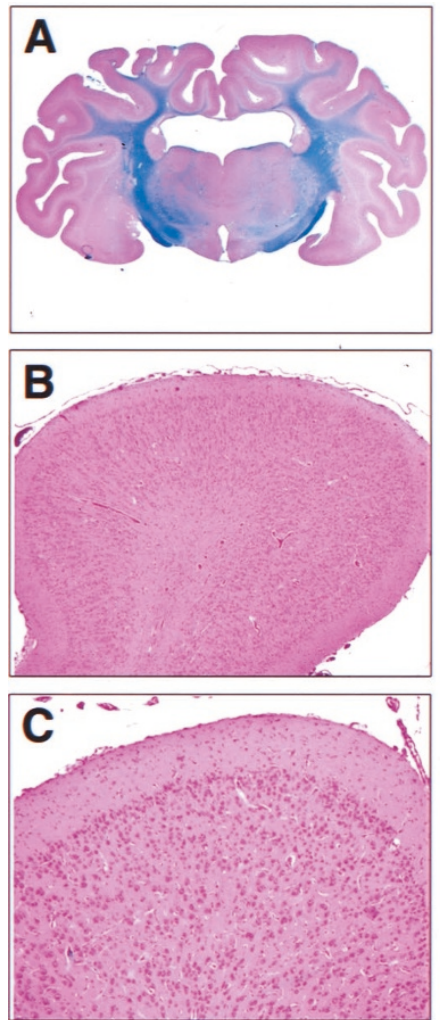

Control
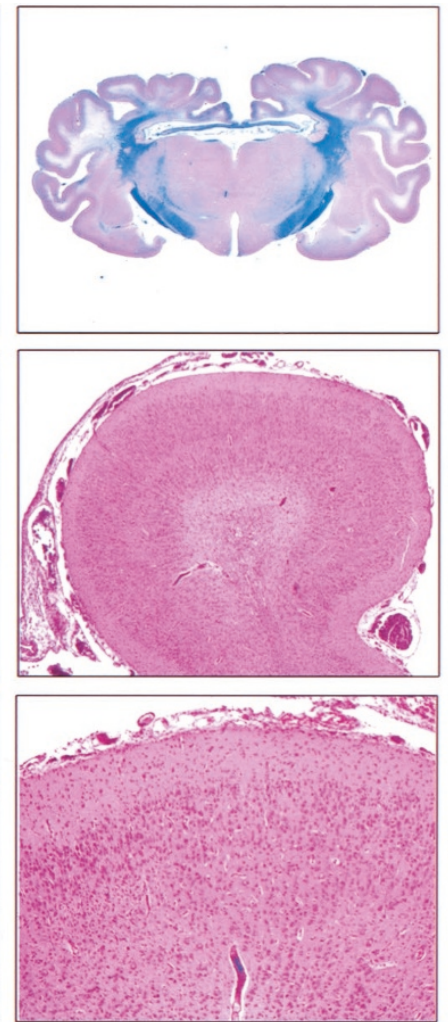

I/R-Glu
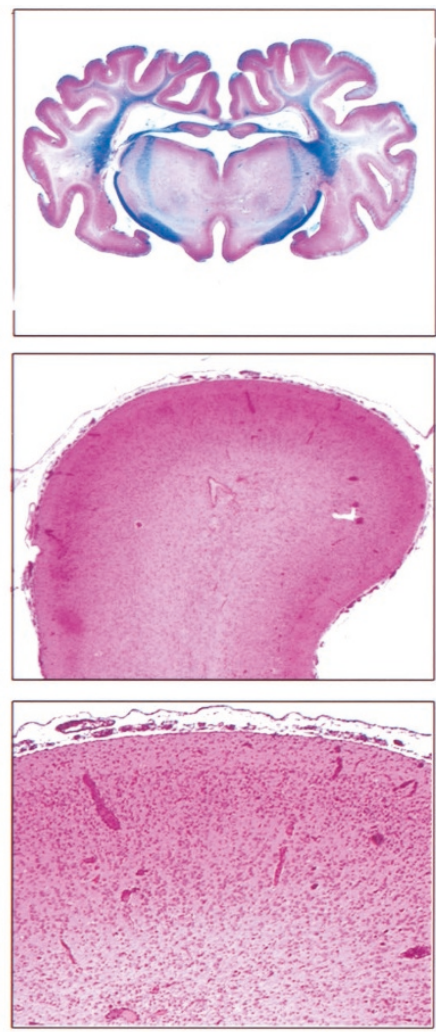

I/R-PL
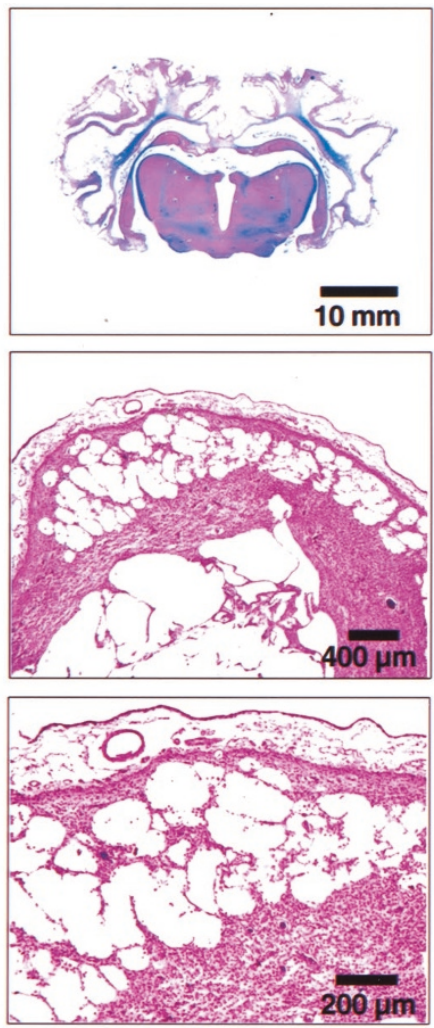

V/R-GluR

Figure 2. Representative whole mount $(A$, top panel, $1 \times)$, white matter $(B$, middle panel, $40 \times)$, and cerebral cortex $(C$, bottom panel, $100 \times)$ coronal brain sections stained with Luxol fast blue-hematoxylin and eosin from glucose-infused fetuses exposed to control treatment (Control), glucose-infused fetuses exposed to bilateral carotid artery occlusion followed by $48 \mathrm{~h}$ of reperfusion (I/R-Glu), placebo-infused fetuses exposed to carotid occlusion and $48 \mathrm{~h}$ of reperfusion (I/R-PL), and glucose-infused fetuses plus rapid glucose injection given before carotid occlusion followed by $48 \mathrm{~h}$ of reperfusion (I/R-GluR). The coronal sections from the control fetus exhibited healthy appearing cerebral cortex and intragyral white matter with homogenously blue-stained myelin. In contrast, the sections from the fetuses exposed to glucose infusion before and during ischemia/reperfusion (I/R-Glu) exhibited damage to the cerebral cortex and white matter. These areas show pallor on Luxol fast blue staining and thinning of the cerebral cortex indicating white matter and neuronal loss, respectively. The sections from the placebo-infused fetuses exposed to ischemia/reperfusion (I/R-PL) exhibited a comparable amount of damage to the cerebral cortex and white matter. The sections from the I/R-GluR group exhibited severe neuronal loss in the cerebral cortex and extensive intragyral white matter loss, manifested by marked pallor on Luxol fast blue staining and microscopic foci of cystic degeneration in both the cortex and white matter.

We have previously demonstrated reproducible white matter and cerebral cortical lesions in ovine fetuses at similar gestational ages using the same method to induce brain injury (40). The reproducibility of this model can be demonstrated by comparing the pathologic scores in the brain regions of the glucose-infused sham control fetuses (cerebral cortex:1.12 \pm 0.13 ; white matter: $0.82 \pm 0.34$; hippocampus: $0.80 \pm 0.34$ ) from the current study with those of our previous work in normoglycemic placebo-infused control fetuses (cerebral cortex: $0.93 \pm 0.09$; white matter: $0.80 \pm 0.33$ and hippocampus: $1.00 \pm 0.00)(40)$. The similarity between the scores in the placebo- and glucose-infused control groups also confirms that exposure to $96 \mathrm{~h}$ of moderate hyperglycemia itself does not result in measurable pathologic brain injury in the sheep fetus.

The pattern of injury observed across the six brain slices also demonstrates the reproducibility of the ischemic brain injury. The I/R-Glu group in the current study (Figs. 3 and 4) exhibited the same pattern as the placebo-infused/ischemic animals exposed to $48 \mathrm{~h}$ of reperfusion in our previous report (40). In both studies, the damage progressed from the frontal cortex (S2), peaking in the regions of the parietal-occipital junction
(S4) and occipital pole (S5), leaving the cerebellum and brain stem (S6) relatively intact. The overall pathologic scores also were similar in the in the whole brain slices and cerebral cortex, white matter, and hippocampus (Figs. 3 and 4) between the I/R-Glu group in the current study and placebo-infused fetuses exposed to the same insult from our previous study (40). Therefore, prolonged exposure to moderate hyperglycemia before, during, and after ischemia does not affect the extent of fetal brain injury resulting from $30 \mathrm{~min}$ of carotid occlusion and $48 \mathrm{~h}$ of reperfusion. However, although we observed significant differences between the control and I/R-Glu groups for equivalent brain slices in Figure 3, when the data were combined to examine changes in the white matter, cortex, and hippocampus in Figure 4, significant differences were not observed between these groups. The lack of differences in the white matter, cerebral cortical, and hippocampal scores between the control and I/R-Glu groups in Figure 4 most likely results from the smaller statistical power, when the combined scores were examined.

The pattern of injury observed in the I/R-GluR group differed considerably from that of the control group exposed to 


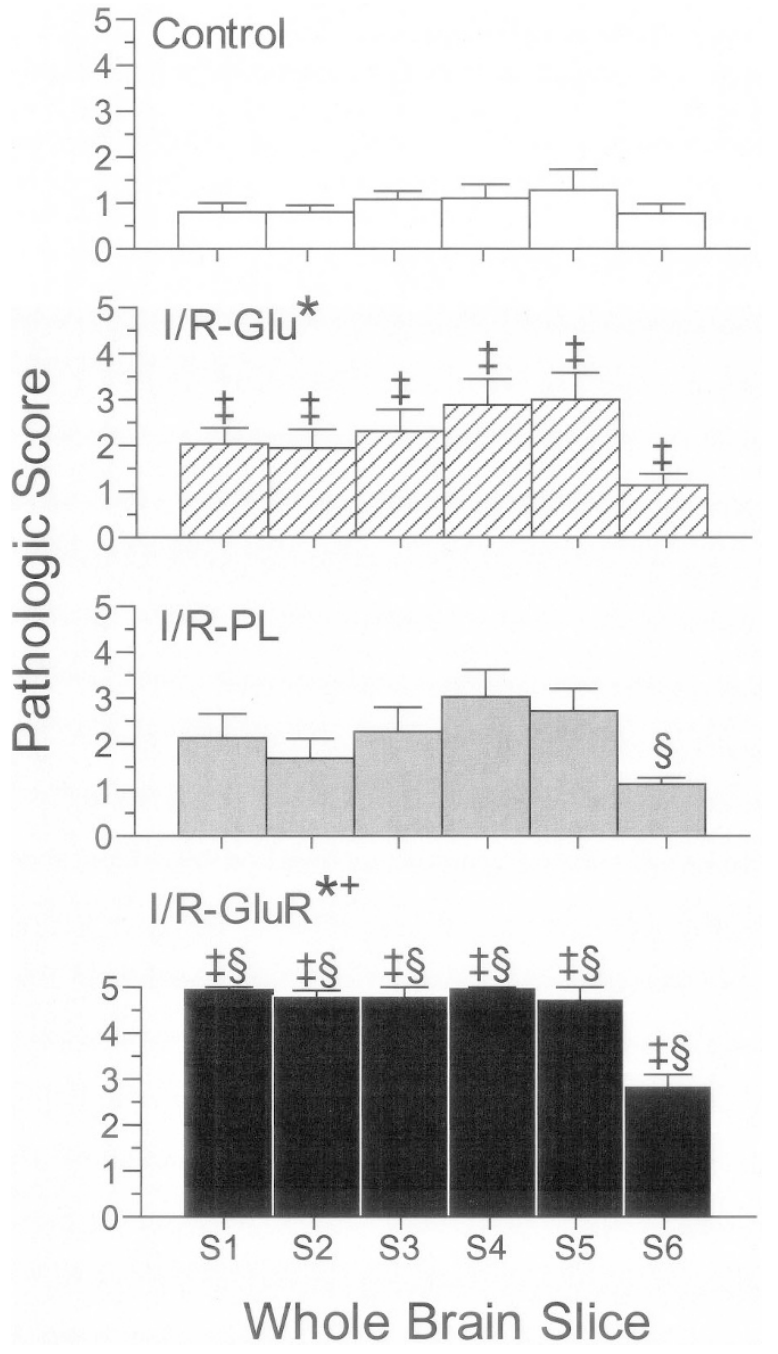

Figure 3. Pathologic scores of the coronally sliced whole brain sections stained with Luxol fast blue-hematoxylin and eosin. All slices received pathologic scores of $0-5$, where $0=0 \%, 1=1-25 \%, 2=26-50 \%, 3=$ $51-75 \%, 4=76-95 \%$, and $5=96-100 \%$ of the area damaged. The brain regions represented within each slice are: slice $1(S 1)$ was prefrontal cortex, slice $2(S 2)$ was frontal cortex, slice $3(S 3)$ was posterior medial eminence, slice $4(S 4)$ was parietal-occipital junction, slice $5(S 5)$ was occipital pole, and slice 6 (S6) was cerebellum and brainstem for the control $(n=5)$, I/R-Glu ( $n$ $=8)$, I/R-PL $(n=8)$, and the I/R-GluR $(n=4)$ groups. Values are mean \pm SEM. *ANOVA, main effects across brain slices $v s$ control group, $p<0.05$; ${ }^{+}$ANOVA, main effect across brain slices $v s$ I/R-Glu group, $p<0.05 ; \ddagger p<$ $0.05 v s$ the equivalent slice in the control group; $\S p<0.05 v s$ the equivalent slice in the I/R-Glu group.

prolonged moderate hyperglycemia without carotid artery occlusion. The addition of a single rapid injection of glucose before ischemia resulted in severe devastating pathologic injury to all brain regions (S1-S5) with less damage in the cerebellum and brain stem (S6, Fig 3.) The level of injury was also severe in the cerebral cortical, white matter and hippocampal regions (Fig. 4).

In our study, we did not examine the effect of a single acute injection of glucose before carotid occlusion on brain injury in normoglycemic fetal sheep. Therefore, we cannot be certain whether the brain damage would have been similar if the fetal sheep had not been exposed to the continuous glucose infusion

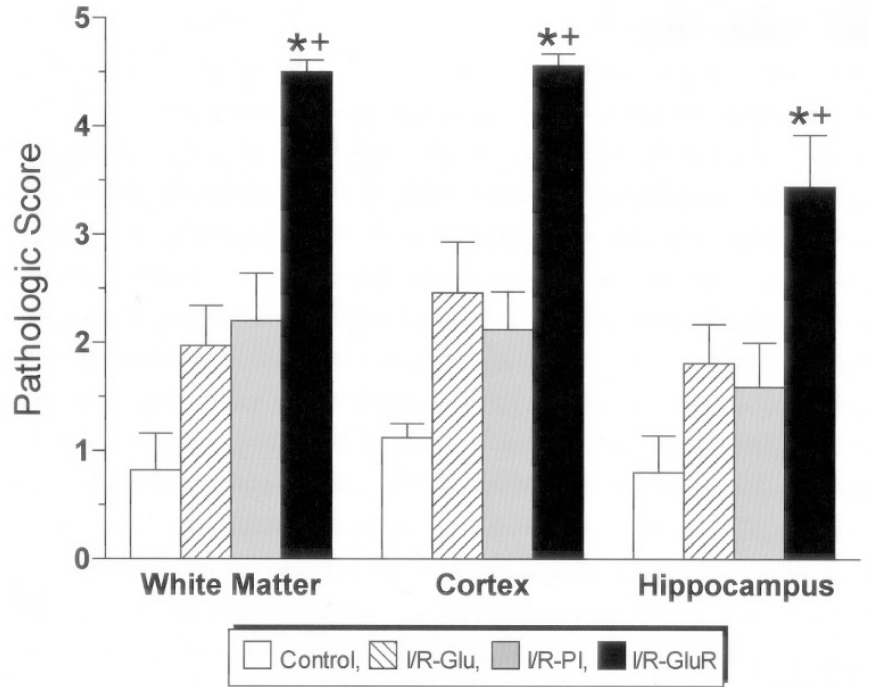

Figure 4. Pathologic scores for white matter, cerebral cortex, and hippocampal damage in the control $(n=5)$, I/R-Glu $(n=8)$, I/R-PL $(n=8)$, and I/R-GluR $(n=4)$ groups. All slices received histologic scores of $0-5$, where $0=0 \%, 1=1-25 \%, 2=26-50 \%, 3=51-75 \%, 4=76-95 \%$, and $5=$ $96-100 \%$ of the area damaged. Values are mean \pm SEM. ${ }^{*} p<0.05 v s$ control group in each region; ${ }^{+} p<0.05 v s$ I/R-Glu group within each region. Data from I/R-PL group has been previously published (40) utilizing the same study design. It was included here for pathologic comparison with the I/R-Glu group.

before the rapid injection of glucose. However, we speculate that the damage might have been greater than we have observed after ischemia and $48 \mathrm{~h}$ of reperfusion in normoglycemic fetal sheep (40).

Premature and newborn infants are often exposed to conditions and therapies, which predispose them to carbohydrate disequilibrium such as prematurity, maternal diabetes, intrauterine growth retardation, sepsis, parenteral nutrition, and glucocorticoid treatment (3). At the same time, they also can be at high risk for hypoxia, hypotension, pneumothoraces, and hemodynamic abnormalities, which could predispose them to brain injury $(10,11)$. The findings of our study may be interpreted to suggest that prolonged exposures to moderate increases in plasma glucose concentrations during these potential episodes would not necessarily exacerbate brain injury.

In our study, we examined 2- to 3-fold increases in plasma glucose concentrations. In the normoglycemic sheep fetus, plasma glucose concentrations are approximately $0.9-1.5 \mathrm{mM}$ and during the glucose infusions, the plasma concentrations ranged from 2.7 to $4.0 \mathrm{mM}$. In the human neonate, normoglycemic values varies from 2.2 to $4.4 \mathrm{mM}(3,49)$. Therefore, based upon our current findings and those of our previous work on the effects of hyperglycemia on the renal function in premature infants (50), prolonged elevations in plasma glucose concentrations, i.e., $5.5-8.3 \mathrm{mM}$, are most likely relatively safe at least with regard to the renal functional changes and their potential affect on brain injury in the neonate. In contrast, acute sudden elevations in plasma glucose concentrations, at a time when neonates are at risk of brain injury, could have severe deleterious effects on the brain.

For the last two decades, delayed neuronal death developing after ischemia has been attributed to the accumulation of lactic 
acid during the ischemic insult $(51,52)$. The frequently referenced study of Myers and Yamaguchi (26) demonstrated that glucose administration terminated shortly before cardiac arrest significantly exacerbated postischemic brain damage. Since that time, hyperglycemia has been shown in numerous studies to exacerbate ischemic damage (12-16). Because hyperglycemia also increases intraischemic lactic acid levels (27-29), it was reasonable to conclude that lactic acidosis itself exacerbates the ischemic brain damage during hyperglycemia. However, the role of glucose in brain injury in the adult as well as juvenile or fetal animals is far from resolved because many studies have failed to show detrimental effects resulting from glucose infusions and some have even shown beneficial effects of preischemic glucose infusions both in vitro (53-56) and in vivo $(21,22,31-33,57,58)$. In addition, several studies have demonstrated that lactate plays an important role in brain energy production $(17,59,60)$ and, rather than exacerbating damage, it might actually attenuate the injury $(17,61)$. However, we cannot comment upon the role of brain lactate concentrations in the brain damage in our study, because we did not measure brain lactate in our fetal sheep.

The timing of the hyperglycemic exposure relative to the ischemic event also could have an important impact on the severity of ischemic damage $(15,20,26)$. It appears that more severe damage develops when glucose infusions are given closer to the time of the ischemic event $(15,20,26)$. Our results are consistent with recent findings that demonstrated that preischemic glucose loading induced short-lived elevations in glucocorticoids that, when present during an ischemic insult, initiated a cascade of events that increased neuronal damage (20). In our study, the significant differences between the fetuses exposed to the continuous-glucose infusion and carotid artery occlusion (I/R-Glu) and those exposed to the continuous glucose-infusion plus the rapid glucose injection before occlusion (I/R-GluR, Figs. 3 and 4) could be due of the timing of the hyperglycemia relative to brain ischemia. However, the differences observed also could be attributed to differences in the levels of hyperglycemia between the groups. Future experiments in the fetus to determine whether the more severe damage in the I/R-GluR than the I/R-Glu group resulted from the timing of the hyperglycemia relative to brain ischemia or level of hyperglycemia would be important.

In the human neonate, dexamethasone treatment can result in hyperglycemia $(62,63)$. Although current recommendations have suggested that this treatment should be limited (64), postnatal steroids are still given to sick, ventilator-dependent infants with bronchopulmonary dysplasia. These infants are at high risk for developing neurodevelopmental impairment (65). Therefore, based upon our findings and those outlined above $(62,63)$, we speculate that the combination of dexamethasone treatment, acute increases in plasma glucose concentrations, and hypoxic/ischemic brain injury (1) could place these infants at even greater risk for neurodevelopmental impairment (65) than their counterparts that are not treated with postnatal steroids and do not develop acute episodes of hyperglycemia.

In summary, we have examined the effects of exposure to moderate prolonged hyperglycemia with and without an additional rapid infusion of glucose on the brain damage after 30 min of bilateral carotid occlusion in the sheep fetus. We conclude that exposure to prolonged moderate hyperglycemia before ischemia and during reperfusion does not affect the extent of ischemic brain damage, but exposure to an additional acute increase in plasma glucose concentration before ischemia is extremely deleterious to the fetal brain.

Acknowledgments. The authors thank Christopher Reilly, Timothy Lee, Amy Yuan, and Cathy Yen for their dedication to this project, and the many students who participated in these studies.

\section{REFERENCES}

1. Vannucci RC 1993 Mechanisms of perinatal hypoxic-ischemic brain damage. Semin Perinatol 7:330-337

2. Volpe JJ 1976 Perinatal hypoxic-ischemic brain injury. Pediatr Clin North Am 23:383-397

3. Cowett RM 1985 Pathophysiology, diagnosis, and management of glucose homeostasis in the neonate. Curr Probl Pediatr 15:1-47

4. Dweck HS 1976 Neonatal hypoglycemia and hyperglycemia: two unique perinatal metabolic problems. Postgrad Med 60:118-124

5. Rudge MV, Calderon IM, Ramos MD, Abbade JF, Rugolo LM 2000 Perinatal outcome of pregnancies complicated by diabetes and by maternal daily hyperglycemia not related to diabetes. A retrospective 10-year analysis. Gynecol Obstet Invest 50:108-112

6. Weintrob N, Karp M, Hod M 1996 Short- and long-range complications in offspring of diabetic mothers. J Diabetes Complications 10:294-301

7. Vannucci RC 2000 Hypoxic-ischemic encephalopathy. Am J Perinatol 17:113-120

8. Volpe JJ 1995 Hypoxic-ischemic encephalopathy: clinical aspects. In Volpe JJ (ed) Neurology of the Newborn. WB Saunders, Philadelphia, PA

9. Jones CW 2001 Gestational diabetes and its impact on the neonate. Neonatal Netw 20:17-23

10. Low JA, Simpson LL, Ramsey DA 1992 The clinical diagnosis of asphyxia responsible for brain damage in the human fetus. Am J Obstet Gynecol 167:11-15

11. Low JA, Froese AB, Galbraith RS, Smith JT, Sauerbrei EE, Derrick EJ 1993 The association between preterm newborn hypotension and hypoxemia and outcome during the first year. Acta Paediatr 82:433-437

12. de-Courten-Myers GM, Kleinholz M, Wagner KR, Myers RE 1989 Fatal strokes in hyperglycemic cats. Stroke 20:1707-1715

13. Weir CJ, Murray GD, Dyker AG, Lees KR 1997 Is hyperglycaemia an independent predictor of poor outcome after acute stroke? Results of a long-term follow up study. BMJ 314:1303-1306

14. Dietrich WD, Alonso O, Busto R 1993 Moderate hyperglycemia worsens acute blood-brain barrier injury after forebrain ischemia in rats. Stroke 24:111-116

15. Pulsinelli WA, Waldman S, Rawlinson D, Plum F 1982 Moderate hyperglycemia augments ischemic brain damage: a neuropathologic study in the rat. Neurology 32:1239-1246

16. Ginsberg MD, Welsh FA, Budd WW 1980 Deleterious effect of glucose pretreatment on recovery from diffuse cerebral ischemia in the cat. I. Local cerebral blood flow and glucose utilization. Stroke 11:347-354

17. Phillis JW, Song D, Guyot LL, O'Regan MH 1999 Lactate reduces amino acid release and fuels recovery of function in the ischemic brain. Neurosci Lett 272:195-198

18. Payne RS, Tseng MT, Schurr A 2003 The glucose paradox of cerebral ischemia: evidence for corticosterone involvement. Brain Res 971:9-17

19. Li PA, He QP, Csiszar K, Siesjo BK 2001 Does long-term glucose infusion reduce brain damage after transient cerebral ischemia? Brain Res 912:203-205

20. Schurr A, Payne RS, Miller JJ, Tseng MT 2001 Preischemic hyperglycemiaaggravated damage: evidence that lactate utilization is beneficial and glucose-induced corticosterone release is detrimental. J Neurosci Res 66:782-789

21. Holowach-Thurston J, Hauhart RE, Jones EM 1974 Anoxia in mice: reduced glucose in brain with normal or elevated glucose in plasma and increased survival after glucose treatment. Pediatr Res 8:238-243

22. Young RS, Petroff OA, Aquila WJ, Cheung A, Gore JC 1992 Hyperglycemia and the rate of lactic acid accumulation during cerebral ischemia in developing animals: in vivo proton MRS study. Biol Neonate 61:235-242

23. LeBlanc MH, Huang M, Patel D, Smith EE, Devidas M 1994 Glucose given after hypoxic ischemia does not affect brain injury in piglets. Stroke 25:1443-1447

24. Blomstrand S, Hrbek A, Karlsson K, Kjellmer I, Lindecrantz K, Olsson T 1984 Does glucose administration affect the cerebral response to fetal asphyxia? Acta Obstet Gynecol Scand 63:345-353

25. Sheldon RA, Partridge JC, Ferriero DM 1992 Postischemic hyperglycemia is not protective to the neonatal rat brain. Pediatr Res 32:489-493

26. Myers RE, Yamaguchi S 1977 Nervous system effects of cardiac arrest in monkeys. Preservation of vision. Arch Neurol 34:65-74

27. Laptook AR, Corbett RJ, Arencibia-Mireles O, Ruley J 1992 Glucose-associated alterations in ischemic brain metabolism of neonatal piglets. Stroke 23:1504-1511

28. Park WS, Chang YS, Lee M 2001 Effects of hyperglycemia or hypoglycemia on brain cell membrane function and energy metabolism during the immediate reoxygenation- 
reperfusion period after acute transient global hypoxia-ischemia in the newborn piglet. Brain Res 901:102-108

29. LeBlanc MH, Huang M, Vig V, Patel D, Smith EE 1993 Glucose affects the severity of hypoxic-ischemic brain injury in newborn pigs. Stroke 24:1055-1062

30. Vannucci RC, Rossini A, Towfighi J 1996 Effect of hyperglycemia on ischemic brain damage during hypothermic circulatory arrest in newborn dogs. Pediatr Res 40:177184

31. McGowan JE, Marro PJ, Mishra OP, Delivoria-Papadopoulos M 1995 Brain cell membrane function during hypoxia in hyperglycemic newborn piglets. Pediatr Res 37:133-139

32. Vannucci RC, Brucklacher RM, Vannucci SJ 1996 The effect of hyperglycemia on cerebral metabolism during hypoxia-ischemia in the immature rat. J Cerebl Blood Flow Metab 16:1026-1033

33. Chao CR, Hohimer AR, Bissonnette JM 1989 The effect of elevated blood glucose on the electroencephalogram and cerebral metabolism during short-term brain ischemia in fetal sheep. Am J Obstet Gynecol 161:221-228

34. Dobbing J, Sands J 1979 Comparative aspects of the brain growth spurt. Early Hum Dev 3:79-83

35. Gleason CA, Robinson R, Harris AP, Mayock DE, Traystman RJ 2002 Cerebrovascular effects of intravenous dopamine infusions in fetal sheep. J Appl Physio 92:717-724

36. Gunn AJ, Gunn TR, de Haan HH, Williams CE, Gluckman PD 1997 Dramatic neuronal rescue with prolonged selective head cooling after ischemia in fetal lambs. J Clin Invest 99:248-256

37. Stonestreet BS, Patlak CS, Pettigrew KD, Reilly CB, Cserr HF 1996 Ontogeny of blood-brain barrier function in ovine fetuses, lambs and adults. Am J Physiol 271:R1594-R1601

38. Sysyn GD, Petersson KH, Patlak CS, Sadowska GB, Stonestreet BS 2001 Effects of postnatal dexamethasone on blood-brain barrier permeability and brain water conten in newborn lambs. Am J Physiol Regul Integ Comp Physiol 280:R547-R553

39. Stonestreet BS, Elitt CM, Markowitz J, Petersson KH, Sadowska GB 2003 Effects of antenatal corticosteroids on regional brain and non-neural tissue water content in the ovine fetus. J Soc Gynecol Investig 10:59-66

40. Petersson KH, Pinar H, Stopa EG, Faris RA, Sadowska GB, Hanumara RC, Stonestreet BS 2002 White matter injury after cerebral ischemia in ovine fetuses. Pediatr Res 51:768-776

41. Williams CE, Gunn AJ, Mallard C, Gluckman PD 1992 Outcome after ischemia in the developing sheep brain: an electroencephalographic and histological study. Ann Neurol 31:14-21

42. Stonestreet BS, Le E, Berard DJ 1993 Circulatory and metabolic effects of betaadrenergic blockade in the hyperinsulinemic ovine fetus. Amer J Physiol 265:H1098 H1106

43. Jackson BT, Egdahl RH 1960 The performance of complex fetal operations in utero without amniotic fluid loss or other disturbances of fetal-maternal relationships. Surgery 48:564-570

44. Mallard EC, Williams CE, Gunn AJ, Gunning MI, Gluckman PD 1993 Frequen episodes of brief ischemia sensitize the fetal sheep brain to neuronal loss and induce striatal injury. Pediatr Res 33:61-65

45. Brown AW, Brierley JB 1972 Anoxic-ischaemic cell change in rat brain light microscopic and fine-structural observations. J Neurol Sci 16:59-84
46. Ott RL, Longnecker M 2001 Statistical Methods and Data Analysis. Duxbury, Pacific Grove, CA, pp 1025-1045

47. Institute SASP 1990 SAS/STAT User's Guide. SAS Institute, Cary, NC, pp 891-997

48. Philipps AF, Porte PJ, Stabinsky S, Rosenkrantz TS, Raye JR 1984 Effects of chronic fetal hyperglycemia upon oxygen consumption in the ovine uterus and conceptus. J Clin Invest 74:279-286

49. Cowett RM, Loughead JL 2002 Neonatal glucose metabolism: differential diagnoses, evaluation, and treatment of hypoglycemia. Neonatal Netw 21:9-19

50. Stonestreet BS, Rubin L, Pollak A, Cowett RM, Oh W 1980 Renal functions of low birth weight infants with hyperglycemia and glucosuria produced by glucose infusions. Pediatrics 66:561-567

51. Siesjo BK 1981 Cell damage in the brain: a speculative synthesis. J Cereb Blood Flow Metab 1:155-185

52. Siesjo BK 1988 Acidosis and ischemic brain damage. Neurochem Pathol 9:31-88

53. Callahan DJ, Engle MJ, Volpe JJ 1990 Hypoxic injury to developing glial cells: protective effect of high glucose. Pediatr Res 27:186-190

54. Schurr A, West CA, Reid KH, Tseng MT, Reiss SJ, Rigor BM 1987 Increased glucose improves recovery of neuronal function after cerebral hypoxia in vitro. Brain Res 421:135-139

55. Yamane K, Yokono K, Okada Y 2000 Anaerobic glycolysis is crucial for the maintenance of neural activity in guinea pig hippocampal slices. J Neurosci Methods 103:163-171

56. Tian GF, Baker AJ 2000 Glycolysis prevents anoxia-induced synaptic transmission damage in rat hippocampal slices. J Neurophysiol 83:1830-1839

57. Ginsberg MD, Prado R, Dietrich WD, Busto R, Watson BD 1987 Hyperglycemia reduces the extent of cerebral infarction in rats. Stroke 18:570-574

58. Schurr A, Payne RS, Tseng MT, Miller JJ, Rigor BM 1999 The glucose paradox in cerebral ischemia. New insights. Ann N Y Acad Sci 893:386-390

59. Pellerin L, Magistretti PJ 1994 Glutamate uptake into astrocytes stimulates aerobic glycolysis: a mechanism coupling neuronal activity to glucose utilization. Proc Nat Acad Sci U S A 91:10625-10629

60. Schurr A, Dong WQ, Reid KH, West CA, Rigor BM 1988 Lactic acidosis and recovery of neuronal function following cerebral hypoxia in vitro. Brain Res 438:311-314

61. Schurr A, Rigor BM 1998 Brain anaerobic lactate production: a suicide note or a survival kit? Dev Neurosci 20:348-357

62. Halliday HL, Patterson CC, Halahakoon CW; Behalf of the European Multicenter Steroid Study Group 2001 A multicenter, randomized open study of early corticosteroid treatment (OSECT) in preterm infants with respiratory illness: comparison of early and late treatment and of dexamethasone and inhaled budesonide. Pediatrics 107:232-240

63. Stark AR, Carlo WA, Tyson JE, Papile LA, Wright LL, Shankaran S, Donovan EF, Oh W, Bauer CR, Saha S, Poole WK, Stoll BJ 2001 Adverse effects of early dexamethasone in extremely-low-birth-weight infants. National Institute of Child Health and Human Development Neonatal Research Network. N Engl J Med 344:95101

64. Grier DG, Halliday HL 2003 Corticosteroids in the prevention and management of bronchopulmonary dysplasia. Semin Neonatol 8:83-91

65. Yeh TF, Lin YJ, Huang CC, Chen YJ, Lin CH, Lin HC, Hsieh WS, Lien YJ 1998 Early dexamethasone therapy in preterm infants: a follow-up study. Pediatrics 101:E7 